\title{
The extraordinary decline of infant and childhood mortality among Palestinian refugees
}

\author{
Marwan Khawaja* \\ Center for Research on Population and Health, Faculty of Health Sciences, American University of Beirut, Beirut, Lebanon
}

\begin{abstract}
This article documents the levels and patterns of infant and child mortality among Palestinian refugees in Jordan, Lebanon and the Palestinian areas based on comparable data from household sample surveys conducted since 1995. The findings show that Palestinian refugees have clear advantage in mortality levels as compared to their non-refugee counterparts in every setting, and refugees living in the camps have similar or lower levels of mortality than their noncamp counterparts, other things being equal. The recent decline of infant and child mortality among this vulnerable segment of the Palestinian population demonstrates the importance of political will in halting the truncation of infant lives. An examination of the mortality patterns by sex and education sheds light on the nature of the decline currently underway.
\end{abstract}

(C) 2003 Elsevier Ltd. All rights reserved.

Keywords: Infant mortality; Childhood mortality; Public health; Palestinian refugees; UNRWA; Political causation

\section{Introduction}

The past decade witnessed a paradigmatic shift in mortality research, and the factors associated with the prevention and control of disease leading to mortality decline. Central to this shift has been the conviction that higher standard of living and good diet are not prerequisites to a mortality transition. It is widely acknowledged by now that per capita income for example correlates poorly with infant mortality rates at the national level (see Preston, 1996). What seems to matter most in achieving low mortality is agencypublic policies targeting the prevention and control of disease through the empowerment of women and the development of a viable health sector (Caldwell, 1986; Jamison, Mosley, Measham, \& Bobadilla, 1993). According to the new paradigm, organised political efforts are seen as having a direct effect on health, largely independent of changes in income or other forms of living standards (Nathanson, 1996, p. 610). Such efforts

*Corresponding author. Tel.: + 961-1-35-00-00; fax: +961-174-44-70.

E-mail address: marwan.khawaja@aub.edu.lb (M. Khawaja). are typically attributed to the actions of a strong and responsive central government. As Szerter (1988, p. 36) states, "the role of ... public health ideology, politics, and medicine operating of necessity through local government, is more correctly seen as the principal causal agency involved" in mortality decline. Yet, until recently, the role of political factors, or human agency, in sparking the mortality transition in the developing world has been largely neglected.

In this brief article, we examine the levels and patterns of infant and child mortality among Palestinian refugees in Jordan, Lebanon and the Palestinian areas based on data from the countries' living conditions surveys conducted since 1995. The Palestinian case provides a unique opportunity to examine the role of agency in mortality decline because the population in question has been largely de-linked from direct state interventions in matters related to public health.

Despite their extremely high fertility (Khawaja, 2000) and relatively low economic status, Palestinians have one of the lowest levels of infant and childhood mortality in the Arab world (Madi, 2000; Pedersen, 2000). However, this remarkable progress has been achieved in the absence of a strong state altogether. We argue that improvement in child health among this 
population occurred because of a long-standing organised effort at the local level on the part of the United Nations Relief and Works Agency (UNRWA) and other civil society organisations. These community-based organisations have been providing preventive health care services and raising the health consciousness among Palestinian refugees in the four settings, but their impact is especially felt in the occupied territories. If our argument were to hold true, we would expect (1) lower (or at least similar) mortality levels among refugees than their non-refugee counterparts in every setting, and (2) relatively low mortality levels among camp refugees as compared to their non-camp counterparts, other things being equal. In addition, we examine mortality patterns by sex and education to shed light on the nature of the decline currently underway.

\section{Methodology}

\section{Sources and quality of data}

Our sources of data are primarily four household surveys undertaken by FAFO Institute in collaboration with local statistical agencies in the four settings. Table 1 displays the main characteristics of the surveys used in the analysis. The first of these is the 1995 National Demographic Survey carried out in co-operation with the Palestinian Central Bureau of Statistics (PCBS, 1997). The survey employed a multi-stage stratified sample design, using a specially constructed sampling frame derived from population estimates and complete household listings of the selected clusters in small areas. A total of 15,683 households were successfully interviewed, with a high response rate of $98 \%$.

The main purpose of the other three surveys was to obtain a wide range of data relevant to living conditions, including detailed demographic information. The FAFO living conditions surveys are remarkably similar in design, content, and definition of variables, making comparative analyses a relatively easy task. There are two recent living conditions surveys available for Jordan: the 1996 Jordan Living Conditions survey of 1996 (Hanssen-Baur, Pedersen, \& Tiltnes, 1998) and the 1999 Refugee Camps Survey (Khawaja \& Tiltnes, 2002). The first survey is based on a national cluster sample of about 6400 households selected randomly from a sample frame based on the 1994 Jordanian Census of population. Face to face interviews with 5920 were successfully interviewed, amounting to an overall response rate of $91.5 \%$. Since this survey was designed to cover the whole population in Jordan, it does not include enough data on Palestinian refugees living in the camps. The Jordan camps survey was undertaken to fill this gap, employing a representative sample of about 3100 households selected randomly from 12 camps. The 1994 Jordan's census of population provides the sampling frame for the camps' survey, after an update using maps available at Jordan's Department of Palestinian Affairs. A response rate of $94.7 \%$ for all household selected was achieved.

Finally, the 1999 survey of the refugee camps in Lebanon is based on a one-stage probability sample of 4000 households living in camps and 'small gatherings'. A small gathering is defined as any agglomeration of at least 25 Palestinian households. The sample was drawn from a frame containing complete listings of households, largely constructed as part of the survey preparatory phase. About 3690 households were successfully interviewed, with a response rate of $97.2 \%$.

\section{Measurement and analysis}

The surveys' birth histories provide data on date of birth, and if the child had died, age at the time of death for each live-born child for ever-married women aged 15-54. Infant and child mortality estimates, for different periods preceding the survey, were calculated directly from these data (see Curtis, 1995). While these retrospective data provide relatively good estimates as

Table 1

Summary of data sources

\begin{tabular}{|c|c|c|c|c|c|c|}
\hline \multirow[t]{2}{*}{ Survey } & \multirow[t]{2}{*}{ Year } & \multicolumn{5}{|l|}{ Sample } \\
\hline & & Coverage & $\begin{array}{l}\text { Number of } \\
\text { households }\end{array}$ & $\begin{array}{l}\text { Number of } \\
\text { women }\end{array}$ & $\begin{array}{l}\text { Number of } \\
\text { live births }\end{array}$ & $\begin{array}{l}\text { Response } \\
\text { rate }\end{array}$ \\
\hline $\begin{array}{l}\text { West Bank and Gaza Strip } \\
\text { demographic survey }\end{array}$ & 1995 & $\begin{array}{l}\text { West Bank and } \\
\text { Gaza Strip }\end{array}$ & 15,683 & 16,204 & 78,490 & 98.2 \\
\hline Jordan living condition survey & 1996 & Jordan & 5920 & 4975 & 23,974 & 91.5 \\
\hline Jordan camps survey & 1999 & 12 camps & 2590 & 2266 & 9851 & 94.7 \\
\hline Lebanon camps survey & 1999 & $\begin{array}{l}\text { All camps and } \\
\text { communities of } \\
\text { Palestinians }\end{array}$ & 3629 & 2899 & 11,977 & 97.2 \\
\hline
\end{tabular}


compared with registration data and demographic models, there are problems specific to these data. The most important of these is the sex-selective omission of children who die during infancy, causing a downward bias in the mortality estimates. Furthermore, the omission, if present, is also selective with respect to the age of women as well as the timing of death. A preliminary examination of sex ratios at birth for dead children indicates some omission of infant girls in the four surveys as would be expected. The reporting of age at death is yet another kind of error affecting the mortality estimates. It is likely that these errors cause some underestimation of infant mortality, but it is doubtful whether they have any significant impact on child mortality (Hill \& Upchurch, 1995, p. 147). We assume that the underestimation is uniform across settings since the analysis is based on the same kind of data and methodology.

Given the descriptive purpose of this study, we rely on bivariate tabulations and simple graphs to describe group differentials in various mortality-related measures by refugee status. We measure refugee status by respondents' straightforward self-identification. All the surveys include a fairly similar question on whether each person in the household is a refugee $(=1)$, or nonrefugee $(=2)$. Although there are other choices for identifying refugees, ${ }^{1}$ the criterion used here is the most defensible one and allows for comparisons with studies of refugees elsewhere. A related variable is camp residence, measured by the type of locality included in the sampling lists. Three types of locality are distinguished in all (non-camps) surveys: camp, village and urban town/city. However, for parsimony, we distinguish only between camps and other localities here.

Similarly, the measurement of education is also comparable across surveys. Education is measured by a four-category ordinal variable: less than elementary, elementary, preparatory and secondary levels of education completed. Elementary education corresponds to the completion of 6 years of schooling, preparatory to 9 years of schooling and secondary educational levels correspond to the completion of 12 years of education. However, the official classification of educational levels in Jordan, adopted in the surveys there, includes 'Basic education' corresponding to the preparatory level without a separate category for elementary education. The highest category used in our analysis includes both secondary and college/university education. Our decision to include these into one category is to simplify the analysis and preserve enough cases in the post-secondary level.

\footnotetext{
${ }^{1}$ One alternative is to use registration with UNRWA. Yet, registration with UNRWA is voluntary and many Palestinian refugees, especially in Jordan and Palestinian territories of Gaza and West Bank, are not registered.
}

\section{Results}

\section{Levels and trends of infant and childhood mortality}

Infant and child mortality rates among refugees are relatively low (Fig. 1). Given the higher economic advantages of non-refugees over refugees and especially camp refugees, one would expect higher mortality levels among refugees. The rates and their $95 \%$ confidence intervals displayed in this graph clearly show the lack of mortality differentials between the groups. Refugees in Jordan and Gaza seem to have even lower infant and child mortality levels than their non-refugee counterparts; the rates for the two groups are essentially similar in the West Bank. With an infant mortality rate (IMR) of about 32 per thousand live births and child mortality, ${ }_{5} q_{0}$, of 37 , during the 5-year period before the survey, refugees in Lebanon's camps had probably the highest levels of infant mortality among refugees. On the other hand, refugees in Jordan had the lowest infant and child mortality levels, 24 and 26 per thousand, respectively. The confidence intervals reported are quite wide, however, owing to the small number of infant deaths, especially in Lebanon and Jordan camps. Recent results from the Jordan camps survey show that the camps' residents have essentially the same rates, 25 and 27 per thousand, 3 years later. As also shown in the graph, the West Bank has probably lower infant mortality rates than Gaza, and this is also the case for refugees. While there is essentially no difference in the infant mortality levels of refugees and non-refugees in the West Bank, the situation in Gaza seems to favour refugees. In Gaza Strip, the refugees have about 5 fewer deaths per thousand than do the non-refugees. This can be partly attributed to the visibility (or accessibility) of UNRWA health services at the local level in Gaza, as compared to the West Bank. However, it should be pointed out that the actual numbers of deaths in these populations are small, and hence, it cannot be established with certainty that the observed differences in some cases are statistically significant. Yet, although the small numbers could be confounding some of the differences, the fact that the refugee population has similar levels of infant and child mortality to the non-refugee population warrants investigation.

Infant and child mortality rates have declined substantially over time in the four settings. However, the speed of the decline varies somewhat between settings. The largest decline occurred in the West Bank and Gaza Strip. Across the two 5-year periods before the survey, IMR fell by $20 \%$ among refugees in the West Bank and Gaza. Likewise, child mortality declined by about the same magnitude (18\%) during the same period. The decline among non-refugees there is slightly larger, amounting to $24 \%$ and $19 \%$, respectively. The trends for Jordan's refugees and Lebanon's camp 


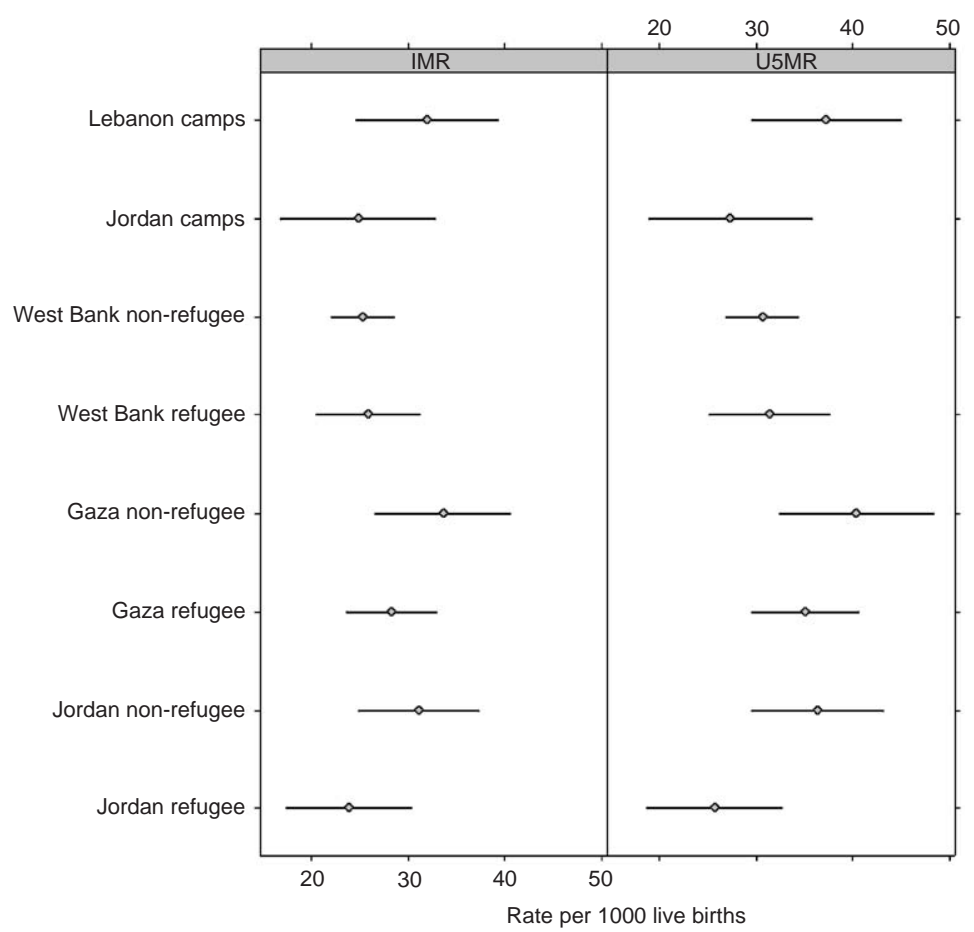

Fig. 1. Infant and child mortality rates (and $95 \%$ confidence intervals) by refugee status. Note: Estimates refer to the 5 years before the surveys. IMR: Infant mortality rate; U5MR: Under 5(child) morality rate.

refugees are similar, but the decline is smaller - infant and child mortality declined by about $8 \%$ and $14 \%$, respectively, in both areas. Jordan's non-refugees, and the camp residents, experienced the slowest decline in mortality during the 10-year period before the survey. The mortality levels were already quite low for camp refugees in Jordan, which may explain the slow pace of the decline in recent years.

\section{Differentials by sex and education of mother}

As expected, infant mortality varies by socio-economic background factors in each of the settings. However, the low levels of infant mortality observed among Palestinians make it difficult to assess the differentials by subgroups-i.e., there are very few deaths. Furthermore, the camps' surveys in Lebanon and Jordan were taken about 5 years later than those for Jordan and the occupied territories so the mortality levels reported here are not strictly comparable. Here, we report infant mortality differentials by sex and maternal education. Infant and childhood mortality levels by these two factors during the 5-year period preceding the surveys are presented in Tables 2 and 3, respectively.

As shown in Table 2, there seems to be an excess infant mortality among boys, compared to girls, in all the settings except Jordan's non-refugees. The gender gap is clear for refugees everywhere, and especially large (16 deaths) in Lebanon's camps. While infant mortality of girls is expected to be lower than that of boys, the gap found in Lebanon is implausibly large. On the other hand, the refugees seem to have lower (or at least similar) mortality levels than the non-refugees; and this is true regardless of gender. However, the gap in mortality levels by refugee status is essentially due to differences in female infant mortality levels. The female infant mortality differentials between refugees and nonrefugee are greatest in Jordan (14 deaths) and Gaza (8 deaths). Otherwise, the similarity between the rates reported in the table for Jordan and the West Bank is quite remarkable.

Infant mortality also varies by maternal education, but the relationship is far from linear. One main conclusion can be ascertained from the table regarding the mortality differentials by education: mothers with secondary education or more have a clear advantage in terms of infant mortality compared to those with less than elementary (defined here as 6 years of formal schooling), regardless of the group in question. Except for the non-refugee mothers in the West Bank, the infant mortality differentials between mothers with the highest and lowest education always exceed 10 deaths per 
Table 2

Infant mortality rates by sex and education of mother

\begin{tabular}{|c|c|c|c|c|c|c|c|c|}
\hline \multirow{2}{*}{$\begin{array}{l}\text { Setting and } \\
\text { group }\end{array}$} & \multirow{2}{*}{$\begin{array}{l}\text { Jordan } \\
\text { camps } \\
(95 \% \mathrm{CI})\end{array}$} & \multirow{2}{*}{$\begin{array}{l}\text { Lebanon } \\
\text { camps } \\
(95 \% \mathrm{CI})\end{array}$} & \multicolumn{2}{|l|}{ Gaza Strip } & \multicolumn{2}{|l|}{ West Bank } & \multicolumn{2}{|l|}{ Jordan } \\
\hline & & & $\begin{array}{l}\text { Refugee } \\
(95 \% \text { CI })\end{array}$ & $\begin{array}{l}\text { Non- } \\
\text { refugee } \\
(95 \% \text { CI })\end{array}$ & $\begin{array}{l}\text { Refugee } \\
(95 \% \text { CI })\end{array}$ & $\begin{array}{l}\text { Non- } \\
\text { refugee } \\
(95 \% \text { CI })\end{array}$ & $\begin{array}{l}\text { Refugee } \\
(95 \% \mathrm{CI})\end{array}$ & $\begin{array}{l}\text { Non-refugee } \\
(95 \% \mathrm{CI})\end{array}$ \\
\hline \multicolumn{9}{|l|}{ Sex } \\
\hline Male & $\begin{array}{l}26.6 \\
(16.5,39.8)\end{array}$ & $\begin{array}{l}39.7 \\
(29.7,52.8)\end{array}$ & $\begin{array}{l}32.9 \\
(27.0,47.1)\end{array}$ & $\begin{array}{l}35.8 \\
(27.0,47.1)\end{array}$ & $\begin{array}{l}29.5 \\
(22.9,39.0)\end{array}$ & $\begin{array}{l}27.6 \\
(23.6,32.9)\end{array}$ & $\begin{array}{l}28.5 \\
(19.9,40.1)\end{array}$ & $\begin{array}{l}29.7 \\
22.5,39.7)\end{array}$ \\
\hline Female & $\begin{array}{l}23.2 \\
(14.2,36.8)\end{array}$ & $\begin{array}{l}23.3 \\
(15.0,33.5)\end{array}$ & $\begin{array}{l}23.4 \\
(18.3,30.6)\end{array}$ & $\begin{array}{l}31.5 \\
(23.0,42.8)\end{array}$ & $\begin{array}{l}21.9 \\
(15.5,29.9)\end{array}$ & $\begin{array}{l}22.8 \\
(18.9,27.9)\end{array}$ & $\begin{array}{l}19.2 \\
(12.6,29.8)\end{array}$ & $\begin{array}{l}32.7 \\
(24.4,42.9)\end{array}$ \\
\hline \multicolumn{9}{|l|}{ Education } \\
\hline $\begin{array}{l}\text { Incomplete } \\
\text { elementary }\end{array}$ & 37.6 & 45.8 & 33.1 & 43.6 & 34.2 & 23.4 & 29.8 & 44.4 \\
\hline & $(24.3,52.8)$ & $(30.2,67.8)$ & $(20.1,49.6)$ & $(30.0,66.3)$ & $(21.2,49.3)$ & $(18.0,30.6)$ & $(12.0,69.9)$ & $(28.6,66.4)$ \\
\hline Elementary ${ }^{\mathrm{a}}$ & - & $\begin{array}{l}24.3 \\
(15.3,36.1)\end{array}$ & $\begin{array}{l}38.1 \\
(29.0,52.6)\end{array}$ & $\begin{array}{l}36.9 \\
(25.3,55.8)\end{array}$ & $\begin{array}{l}27.1 \\
(18.8,39.7)\end{array}$ & $\begin{array}{l}27.7 \\
(21.8,34.6)\end{array}$ & - & - \\
\hline \multirow[t]{2}{*}{$\begin{array}{l}\text { Preparatory/ } \\
\text { basic }\end{array}$} & 9.2 & 33.0 & 27.1 & 33.9 & 26.3 & 23.7 & 27.2 & 26.1 \\
\hline & $(1.8,25.9)$ & $(20.3,52.5)$ & $(20.4,37.1)$ & $(23.2,49.1)$ & $(18.6,39.4)$ & $(18.5,30.6)$ & $(19.1,38.5)$ & $(19.1,35.1)$ \\
\hline \multirow{2}{*}{$\begin{array}{l}\text { Secondary or } \\
\text { more }\end{array}$} & 17.2 & 30.6 & 21.4 & 20.9 & 15.6 & 26.8 & 18.3 & 32.2 \\
\hline & $(7.7,31.9)$ & $(14.5,60.4)$ & $(15.4,29.3)$ & $(11.8,36.14)$ & $(8.0,27.2)$ & $(20.0,36.2)$ & $(10.7,29.4)$ & $(22.3,45.5)$ \\
\hline
\end{tabular}

Source: See Table 1.

Note: Estimates refer to the 5-years before the survey.

${ }^{\mathrm{a}}$ For Jordan, elementary and preparatory levels are combined into basic.

Table 3

Child mortality rates by sex and education of mother

\begin{tabular}{|c|c|c|c|c|c|c|c|c|}
\hline \multirow{2}{*}{$\begin{array}{l}\text { Setting and } \\
\text { group }\end{array}$} & \multirow{2}{*}{$\begin{array}{l}\text { Jordan } \\
\text { camps } \\
(95 \% \mathrm{CI})\end{array}$} & \multirow{2}{*}{$\begin{array}{l}\text { Lebanon } \\
\text { camps } \\
(95 \% \text { CI })\end{array}$} & \multicolumn{2}{|l|}{ Gaza Strip } & \multicolumn{2}{|l|}{ West Bank } & \multicolumn{2}{|l|}{ Jordan } \\
\hline & & & $\begin{array}{l}\text { Refugee } \\
(95 \% \text { CI })\end{array}$ & $\begin{array}{l}\text { Non- } \\
\text { refugee } \\
(95 \% \text { CI })\end{array}$ & $\begin{array}{l}\text { Refugee } \\
(95 \% \text { CI })\end{array}$ & $\begin{array}{l}\text { Non- } \\
\text { refugee } \\
(95 \% \mathrm{CI})\end{array}$ & $\begin{array}{l}\text { Refugee } \\
(95 \% \text { CI })\end{array}$ & $\begin{array}{l}\text { Non-refugee } \\
(95 \% \mathrm{CI})\end{array}$ \\
\hline \multicolumn{9}{|l|}{ Sex } \\
\hline Male & $\begin{array}{l}28.2 \\
(18.6,43.2)\end{array}$ & $\begin{array}{l}45.5 \\
(34.3,58.3)\end{array}$ & $\begin{array}{l}40.9 \\
(35.93,52.5)\end{array}$ & $\begin{array}{l}43.5 \\
(35.5,59.1)\end{array}$ & $\begin{array}{l}32.3 \\
(26.6,44.3)\end{array}$ & $\begin{array}{l}34.1 \\
(30.9,41.8)\end{array}$ & $\begin{array}{l}29.1 \\
(21.5,42.8)\end{array}$ & $\begin{array}{l}35.8 \\
(27.8,46.8)\end{array}$ \\
\hline Female & $\begin{array}{l}26.5 \\
(16.5,40.8)\end{array}$ & $\begin{array}{l}28.1 \\
(18.4,38.0)\end{array}$ & $\begin{array}{l}29.0 \\
(24.4,38.8)\end{array}$ & $\begin{array}{l}37.2 \\
(28.4,50.4)\end{array}$ & $\begin{array}{l}29.8 \\
(23.0,40.6)\end{array}$ & $\begin{array}{l}27.1 \\
(23.9,24.3)\end{array}$ & $\begin{array}{l}22.4 \\
(15.4,34.6)\end{array}$ & $\begin{array}{l}37.0 \\
(28.9,48.9)\end{array}$ \\
\hline \multicolumn{9}{|l|}{ Education } \\
\hline $\begin{array}{l}\text { Incomplete } \\
\text { elementary }\end{array}$ & $\begin{array}{l}41.2 \\
(28.1,57.9)\end{array}$ & $\begin{array}{l}52.0 \\
(33.0,69.8)\end{array}$ & $\begin{array}{l}40.1 \\
(24.7,56.4)\end{array}$ & $\begin{array}{l}49.0 \\
(32.8,69.4)\end{array}$ & $\begin{array}{l}44.1 \\
(29.1,59.4)\end{array}$ & $\begin{array}{l}31.0 \\
(24.3,38.2)\end{array}$ & $\begin{array}{l}35.4 \\
(13.5,69.0)\end{array}$ & $\begin{array}{l}49.5 \\
(31.1,67.7)\end{array}$ \\
\hline Elementary ${ }^{\mathrm{a}}$ & - & $\begin{array}{l}30.1 \\
(20.4,43.1)\end{array}$ & $\begin{array}{l}40.1 \\
(32.0,57.18)\end{array}$ & $\begin{array}{l}43.5 \\
(30.5,64.6)\end{array}$ & $\begin{array}{l}30.9 \\
(23.1,46.5)\end{array}$ & $\begin{array}{l}30.6 \\
(25.6,39.7)\end{array}$ & - & - \\
\hline \multirow[t]{2}{*}{$\begin{array}{l}\text { Preparatory/ } \\
\text { basic }\end{array}$} & 10.9 & 37.4 & 35.7 & 44.0 & 33.1 & 29.0 & 28.2 & 30.9 \\
\hline & $(3.6,33.8)$ & $(22.5,55.4)$ & $(29.5,49.9)$ & $(33.4,65.3)$ & $(25.7,50.8)$ & $(25.4,40.2)$ & $(20.0,40.0)$ & $(23.6,41.1)$ \\
\hline \multirow{2}{*}{$\begin{array}{l}\text { Secondary or } \\
\text { more }\end{array}$} & 18.1 & 34.2 & 30.0 & 24.6 & 16.8 & 33.0 & 19.9 & 38.3 \\
\hline & $(9.5,36.3)$ & $(17.4,66.9)$ & $(23.7,41.3)$ & $(15.1,42.9)$ & $(9.0,30.4)$ & $(27.9,47.9)$ & $(14.2,36.7)$ & $(29.4,56.4)$ \\
\hline
\end{tabular}

Source: See Table 1.

Note: Estimates refer to the 5-years before the survey.

${ }^{\mathrm{a}}$ For Jordan, elementary and preparatory levels are combined into basic. 
thousand, and reach 20 deaths or more in Jordan's camps and among Gaza's non-refugees. Clearly, the relationship between education and infant mortality is far from uniform.

Generally, the same conclusions reported above apply as well to child mortality differentials (Table 3). While secondary education (or more) still holds a visible advantage in reducing the risk of child death, the relationship between mortality and education is even less consistent here. Thus mothers with elementary or basic education have the lowest child mortality levels among 4 of the 8 groups in the four settings.

\section{Discussion}

Over 50 years have passed since the creation of the Palestinian refugee problem during, or immediately after, the 1948-1949 war. One can no longer consider refugee status as a fundamental determining factor of Palestinian mortality. For, the refugee population has become more differentiated over the past 50 years or so, with those residing outside the camps having generally better living conditions than their camp counterparts (Doan \& Bisharat, 1990). Thus, camp residence is still relevant everywhere regardless of the legal status of refugees in question.

Infant and childhood mortality levels are relatively high in the Lebanese camps, but the levels seem lower (or at least similar) among the refugees and non-refugees everywhere else. Furthermore, refugees seem to have similar or lower mortality levels than non-refugees regardless of gender or education. Although the patterns are generally clear and consistent, there is overlap in the confidence intervals reported for some cases suggesting the lack of statistically significant differences between some groups. Yet, although the small number of cases could be confounding some of these results, the fact that camp refugee mortality is at levels similar to the host populations warrants explanation. For, camp refugee populations are expected to have much higher mortality levels than the host population given their much lower income or otherwise concentrated poverty (Khawaja \& Tiltnes, 2002).

There are two unusual trends concerning mortality differentials, however. First, the gender gap observed in mortality levels favouring girls among refugees is evident, and the one found in Lebanon camps is implausibly large. It was suggested that this might be due to an underreporting of female deaths in the Lebanon survey, or to wide vaccination coverage during the period after the civil war of 1976-1991, or to the demise of certain gender-specific diseases, or to all of these factors (Khawaja, 2003). Second, there are educational differentials in mortality levels but some of these differentials do not seem statistically significant; and the relationship between education and mortality is far from consistent. This might be due to a number of factors including the small number of events (especially in Jordan's camp survey), measurement problems of educational levels, or to selective underreporting of deaths. However, we argue that the distorted relationship is due to better access and utilisation of health care services by the low educated groups. In other words, widespread health services (mainly provided by UNRWA) targeting disadvantaged mothers and children might be behind the observed pattern. It remains that infant and child mortality rates declined over time in every setting.

The decline of infant and child mortality among the vulnerable segment of the Palestinian population demonstrates the importance of political will in halting the truncation of infant lives. The uniqueness of this case is that the decline has occurred despite the lack of explicit health policy or the direct involvement of the national state. It is beyond the scope of this note to establish the precise pathways of mortality decline among this population. However, a plausible explanation may consist of several political factors.

Chief among these factors is the Arab-Israeli conflict. In the course of conflict, health has become a strategic site of public concern. On the one hand, it is an area where competing political organisations can use for gaining legitimacy and larger followings (i.e., mobilisation). It is widely known now that various political factions in the West Bank, Gaza and Lebanon operated health or medical service organisations at the local level with varying degrees of success. For example, the creation of a "parallel health infrastructure" during the course of the Intifada constituted a vibrant social movement operating at the grass-root level (Barghouti \& Giacaman, 1990). Raising health consciousness among Palestinians and providing preventive health care services are the main stated objectives of such movements, though the hidden agenda was probably political mobilisation. On the other hand, conflict has some bearing on peoples' values of health in a more direct way due to the constant threat of personal security and sheer survival. "For the Palestinians, improvements in health status becomes a means of resistance" to occupation (Fargues, 2000, p. 467).

Secondly, UNRWA and indigenous non-governmental organisations were able to mobilise enough resources to create and sustain a viable health infrastructure, including maternity health care clinics (Fargues, 2000). UNRWA in particular has played a major role in providing health care services to camp refugees, arguably the most disadvantaged segment of the Palestinian population in the occupied areas and elsewhere. The prolonged conflict made it possible for UNRWA and other local organisations to amass 
resources and other kinds of assistance from external sources, mainly through international aid.

Given the prevailing levels of infant mortality among the Palestinians, it is doubtful that the decline will continue at the same pace. The evidence from Jordan, and to some extent the West Bank, shows that the decline has been slowing down during the most recent period. Furthermore, the decline has been largely due to improvements in the survival chances of female infants, and the sex pattern of mortality is now similar to that of developed countries. Lebanon is clearly an exception here, but one cannot expect a speedy reduction in female infant deaths elsewhere.

\section{Conclusions}

The findings reported in this paper clearly show that Palestinian refugees, including those still living in refugee camps, have fairly similar (and in some cases lower) infant and childhood mortality levels to their non-refugee counterparts. Furthermore, infant and child mortality rates have declined over time in the four settings, especially among refugees. However, the speed of the decline varies somewhat between settings. Most of the decline is attributed to improvement in child survival among girls, and there is an excess (infant and child) mortality among refugee boys, compared to girls, in all the settings. Finally, mothers with secondary education or more have a clear advantage in terms of infant survival compared to those with less than elementary education.

Our findings underscore the importance of nongovernmental organisations in improving preventive (public and personal) health practices, and hence speeding mortality improvement, among populations in unusual circumstances. The social policy implications is that state intervention, with programs directly targeting nutrition and standard of living, are not the only alternative as explanations to mortality reduction. This is not to argue that the effects of nutrition or standard of living on mortality are negligible; nor would we argue that policies to reduce the burden of disease in impoverished contexts be ignored. However, preventive health practices, the spread of information regarding personal hygiene and control of disease (Caldwell, Reddy, \& Caldwell, 1983), and raising health consciousness among disadvantaged groups, probably play a pivotal role in speeding mortality improvement. Policies and interventions that enhance the role of local organisations in addressing these aspects in impoverished settings, especially of other refugees, warrant considerations.

However, explaining changes in infant and child mortality levels both across space (or group) and over time is a complex undertaking. This rather descriptive portrait of the mortality experience of Palestinian refugees provides the basis for further studies that confirm (or refute) the findings presented here. Future research is also needed to examine the potential role of local organisations in improving child health among other refugee populations. While a comprehensive theory of mortality decline is still lacking, it is widely believed by now that such a theory should be multidimensional in scope consisting of individual (education, women's autonomy, etc.), group (e.g., refugee status) as well as contextual (community as well national-level) socio-economic and political factors. Future research must go beyond compositional factors (sex, age, education) to include relevant political, economic, and social influences on child health if we are to achieve adequate explanations of changes in mortality levels. This line of research will require the use of national-level survey data and multi-level analytic techniques, which have recently become widely available.

\section{Acknowledgements}

The survey data on which the analysis is based are gathered with generous support from the Government of Norway and the European Commission.

\section{References}

Barghouti, M., \& Giacaman, R. (1990). The emergence of an infrastructure of resistance: The case of health. In J. Nassar, \& R. Heacock (Eds.), Intifada: Palestine at the crossroads (pp. 73-87). New York: Preager.

Caldwell, J. C. (1986). Routes to low mortality in poor countries. Population and Development Review, 12, 171-220.

Caldwell, J. C., Reddy, P. H., \& Caldwell, P. (1983). The social component of mortality decline. An investigation in South India employing alternative methodologies. Population Studies, 37, 185-205.

Curtis, S. L. (1995). Assessment of the quality of the data used for direct estimation of infant and child mortality in DHS-II surveys. Occasional Papers 3. Culverton, MD: Macro International Inc.

Doan, R. M., \& Bisharat, L. (1990). Female autonomy and child nutritional status: The extended family residential unit in Amman, Jordan. Social Science \& Medicine, 31, 783-789.

Fargues, P. (2000). Protracted national conflict and fertility change among Palestinians and Israelis. Population and Development Review, 26, 441-482.

Hanssen-Baur, J., Pedersen, J., Tiltnes, A. (Eds.). (1998). Jordanian society: The Jordan living conditions survey. Oslo: FAFO.

Hill, K., \& Upchurch, D. M. (1995). Evidence of gender differences in child health from the Demographic and Health Surveys. Population and Development Review, 21, 127-151. 
Jamison, D. T., Mosley, W. H., Measham, A. R., Bobadilla, J. L. (Eds.), (1993). Disease control priorities in developing countries. New York: Oxford University Press.

Khawaja, M. (2000). The recent rise in Palestinian fertility in the West Bank and Gaza Strip. Permanent or transient? Population Studies, 54, 331-346.

Khawaja, M. (2003). Population. In Ole. Fr. Ugland (Ed.), Difficult past, uncertain future: living conditions among Palestinian refugees in camps and gatherings in Lebanon (pp. 29-60). Oslo: FAFO.

Khawaja, M., Tiltnes, A. (Eds.). (2002). On the margins: Migration and living conditions of Palestinian camp refugees in Jordan. Oslo: FAFO.

Madi, H. (2000). Infant and childhood mortality among Palestinian refugees. The Lancet, 356(9226), 312.
Nathanson, C. A. (1996). Disease prevention as social change: Toward a theory of public health. Population and Development Review, 23, 609-638.

PCBS, (1997). The demographic survey in the West Bank and Gaza Strip: Final report. Ramallah: Palestinian Central Bureau of Statistics.

Pedersen, J. (2000). Determinants of infant morality in the West Bank and Gaza Strip. Journal of Biosocial Science, 32, 527-546.

Preston, S. (1996). Population studies of mortality. Population Studies, 50, 525-536.

Szreter, S. (1988). The importance of social intervention in Britain's mortality decline c. 1850-1914: A reinterpretation of the role of public health. Social History of Medicine, 1, $1-37$. 